\title{
Expression of the Vesicular Monoamine Transporter Gene Solute Carrier Family 18 Member 1 (SLC18A1) in Lung Cancer
}

\author{
STEVEN LEHRER ${ }^{1}$ and PETER H. RHEINSTEIN ${ }^{2}$ \\ ${ }^{1}$ Fermata Pharma, Inc., New York, NY, U.S.A.; \\ ${ }^{2}$ Severn Health Solutions, Severna Park, MD, U.S.A.
}

\begin{abstract}
Background: One aspect of smoking and lung cancer that has not been closely examined, is that regarding genes that may predispose to tobacco dependence. Smoking and mental illness are tightly linked, apparently the result of smokers using cigarettes to self-medicate for mental problems. The gene for solute carrier family 18 member Al (vesicular monoamine transporter; SLC18A1) is of particular interest in this regard because of its association with schizophrenia, autism and bipolar illness as well as with cancer. In the current study, the relationship of SLC18A1 expression with smoking and lung cancer was analyzed. Materials and Methods: The association between smoking, SLC18A1 expression and overall survival in the lung cancer dataset in The Cancer Genome Atlas was evaluated using the Genomic Data Commons Data Portal (https://portal.gdc.cancer.gov), as well as CbioPortal for Cancer Genomics (http://www.cbioportal.org) and the University of California Santa Cruz Xena browser (https://xenabrowser.net). Results: Increased expression of SLC18A1 was found to be associated with a significantly increased survival in patients with adenocarcinoma ( $p=0.0058)$, but not those with squamous carcinoma $(p=0.96)$. Lifelong never-smokers had the highest SLC18A1 expression. In the Pan Cancer Atlas, increased expression of SLC18A1 places such a tumor in group C5, among immunologically- quiet tumors. Conclusion: Most neversmokers with lung cancer do not respond to immune checkpoint inhibitors (ICIs). But for unknown reasons, a small proportion do show clinical benefit from the ICI pembrolizumab. Because of the good response of this group,
\end{abstract}

This article is freely accessible online.

Correspondence to: Dr. Steven Lehrer, Fermata Pharma, Inc. 30 West 60th Street, New York, NY 10023-7909, U.S.A. E-mail: steven@fermatapharma.com

Key Words: Pembrolizumab, nivolumab, lung cancer, the Cancer Genome Atlas, SLC18A1. it may be worthwhile assessing their SLC18A1 expression pre-treatment as a marker for potential clinical benefit. If SLC18A1 expression is low, a never-smoker may respond well to ICIs. High levels of expression would indicate a C5 tumor less likely to respond to ICIs. SLC18A1 might complement other biomarkers currently under study in relation to programmed cell death protein 1/programmed cell death protein ligand 1 inhibition.

Lung cancer is the most common malignancy and the primary cause of cancer-related deaths worldwide. The genetics of lung cancer has been the subject of intense investigation. Epidermal growth factor receptor $(E G F R)$, Kirsten rat sarcoma virus (KRAS), phosphatidylinositol-4,5-bisphosphate 3-kinase, catalytic subunit alpha (PIK3CA), and P53 or tumor protein 53 (TP53) genes are frequently mutated (1). Inhibitors of programmed death 1 (PD1) and its ligand PD-L1 are effective therapies for metastatic non-small-cell lung cancer (NSCLC) lacking sensitizing EGFR or anaplastic lymphoma kinase $(A L K)$ mutations. Pembrolizumab (Keytruda, Merck), nivolumab (Opdivo, Bristol-Myers Squibb), and atezolizumab (Tecentriq, Genentech) are effective in smokers with stage IV disease, but not in never-smokers $(2,3)$.

Cigarette smoking significantly increases lung cancer risk and results in genetic changes. Tobacco smoke contains more than 60 mutagens capable of binding to and chemically modifying DNA, and these alterations leave characteristic mutational patterns seen in lung cancers. For example, distinctive point mutation patterns in KRAS and TP53 have been observed in patients with lung cancer with a history of smoking versus their non-smoking counterparts (1).

One aspect of smoking and lung cancer that has not been closely examined is that regarding genes which may predispose to tobacco dependence. Smoking and mental illness are tightly linked. In an Israeli study, the rate of smoking did not appear to differ between bipolar (43.0\%) and schizophrenic (45.0\%) patients, whereas the rate for both patient groups was higher than that for the general Israeli population (27.5\%) (4). The link to smoking is apparently the result of smokers using cigarettes to self-medicate for mental problems (5). 
The solute carrier family 18 member A1 (vesicular monoamine transporter) gene SLC18Al is of particular interest because of its association with schizophrenia (6-10), autism (11) and bipolar illness (9) as well as with cancer (12, 13). In the current study, the relationship of SLC18Al expression with smoking and lung cancer was analyzed.

\section{Materials and Methods}

The association between smoking, SLC18Al expression and overall survival in the lung cancer dataset in The Cancer Genome Atlas (TCGA) was evaluated. To access and analyze the data the following were used: Genomic Data Commons Data Portal (https://portal.gdc.cancer.gov); University California Santa Cruz Xena browser (https://xenabrowser.net); and CbioPortal for Cancer Genomics (http://www.cbioportal.org/)

SLC18A1 expression is quantified as RNAseq count. The normalized unit for count is $\log 2($ norm_count +1$)$. The normalization calculation is described elsewhere (14).

Data selection. The entire TCGA lung cancer data set was analyzed (1,299 cases).

The following features were assessed: Effect of SLC18A1 on survival; expression of $S L C 18 A 1$ by smoking status; frequency of genetic alteration of $S L C 18 A 1$ in lung cancer according to histology; SLC18A1 expression in the TCGA PanCan Atlas. Endpoints were death or last time-point the patient was known to be alive. Survival analyses were carried out by the method of Kaplan and Meier (15).

\section{Results}

A total of 1,299 patients were included in the sample; $43.5 \%$ were women, $56.5 \%$ were men. Their mean age was $66 \pm 9$ years. Table I lists the pathological stages of the tumors included.

The effect of SLC18A1 on survival is shown in Figure 1. Note that higher expression of SLC18Al was found to be associated with significantly increased survival of patients with adenocarcinoma $(p=0.0058)$ but not of those with squamous carcinoma $(p=0.96)$. Number of patients in each group is shown above corresponding error bar. The high/low survival cutoff was identified by methods described in the R2 web-based application (http://r2.amc.nl); the method divides the sample, in ascending order of gene expression, into two equal-sized groups.

In those with adenocarcinoma, increased SLC18Al expression and increased survival (284 patients out of 564 total) were probably due to the fact that never-smokers reportedly have better survival than smokers (16), as well as higher SLC18Al expression (Figure 2). In a separate analysis, SLC18A1 was more highly expressed in 527 squamous cell carcinomas compared to 364 adenocarcinomas (mean $\pm \mathrm{SEM}=4.5 \pm 0.08$ versus $3.5 \pm 0.14$, respectively).

Expression of SLC18Al according to smoking status is shown in Figure 2 ( $p=0.035$ one-way ANOVA). Lifelong never-smokers had the highest expression.
Table I. Pathological stage of tumors analyzed.

\begin{tabular}{lrccc}
\hline & Frequency & Percentage & $\begin{array}{c}\text { Valid } \\
\text { percentage }\end{array}$ & $\begin{array}{c}\text { Cumulative } \\
\text { percentage }\end{array}$ \\
\hline Valid & 82 & 6.3 & 6.3 & 6.3 \\
Stage I & 8 & 0.6 & 0.6 & 6.9 \\
Stage IA & 266 & 20.5 & 20.5 & 27.4 \\
Stage IB & 354 & 27.3 & 27.3 & 54.7 \\
Stage II & 5 & 0.4 & 0.4 & 55 \\
Stage IIA & 131 & 10.1 & 10.1 & 65.1 \\
Stage IIB & 203 & 15.6 & 15.6 & 80.8 \\
Stage III & 3 & 0.2 & 0.2 & 81 \\
Stage IIIA & 169 & 13 & 13 & 94 \\
Stage IIIB & 36 & 2.8 & 2.8 & 96.8 \\
Stage IV & 42 & 3.2 & 3.2 & 100 \\
Total & 1299 & 100 & 100 & \\
\hline
\end{tabular}

Frequency of alteration of SLC18A1 in 1,299 lung cancers according to histology is shown in Figure 3. PDCDl (the PD1 gene) and SLC18A1 have four significantly co-occurent alterations $(p=0.011)$ in lung adenocarcinoma, suggesting that these two genes might play a similar role or need to interact (17). PDCDI alterations are shown in Table II.

SLC18A1 expression in the TCGA PanCan Atlas was examined. The Pan Cancer Atlas includes the analyses of over 11,000 tumors from 33 of the most prevalent forms of cancer. Expression of SLC18A1 places it in group C5, immunologically quiet tumors (Figure 4). This group consists mostly of lower grade brain gliomas, exhibiting the lowest lymphocyte and highest macrophage responses, dominated by M2 macrophages (18). SLC18Al is most highly expressed in pheochromocytoma and paraganglioma (Figure 5). SLC18AI expression in 7,903 PanCan Atlas samples is shown in Figure 6 . This gene is not highly expressed in most tumors but might represent a biomarker and a therapeutic target. Information on gene program score is included in the figure (19).

\section{Discussion}

SLC18A1 acts to accumulate cytosolic monoamines into vesicles, using the proton gradient maintained across the vesicular membrane. The transporter is a site of action of drugs, including reserpine and tetrabenazine (20). Its normal function is essential for the correct activity of the monoaminergic systems that have been implicated in neuropsychiatric disorders. SLC18A1 maps to chromosome 8p23.1, a region of genes associated with personality traits (21). SLC18A1 rs1390938/Thr136Ile is associated with mood, depression, personality, and alcohol use in the general population $(22,23)$. Individuals homozygous for the 'hyperfunction' allele (AA; Ile/Ile) appear to be more resilient to these disorders (24). 

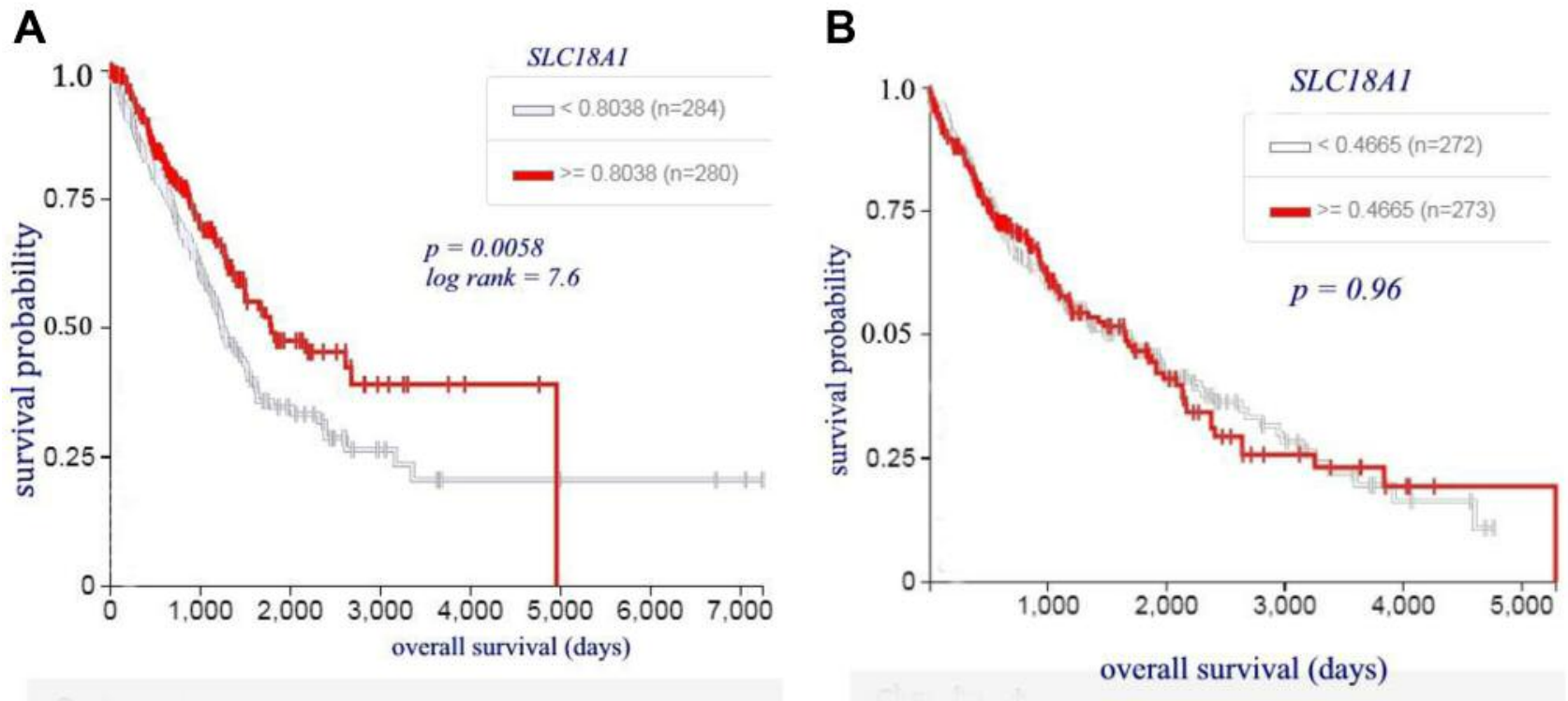

Figure 1. Survival analysis of patients with lung cancer. Note the significant effect of higher solute carrier family 18 member 1 (SLC18A1) expression $[\log 2($ norm_count +1$)]$ on survival of those with adenocarcinoma $(A)$, but the absence of such effect in those with squamous cell carcinoma $(B)$.

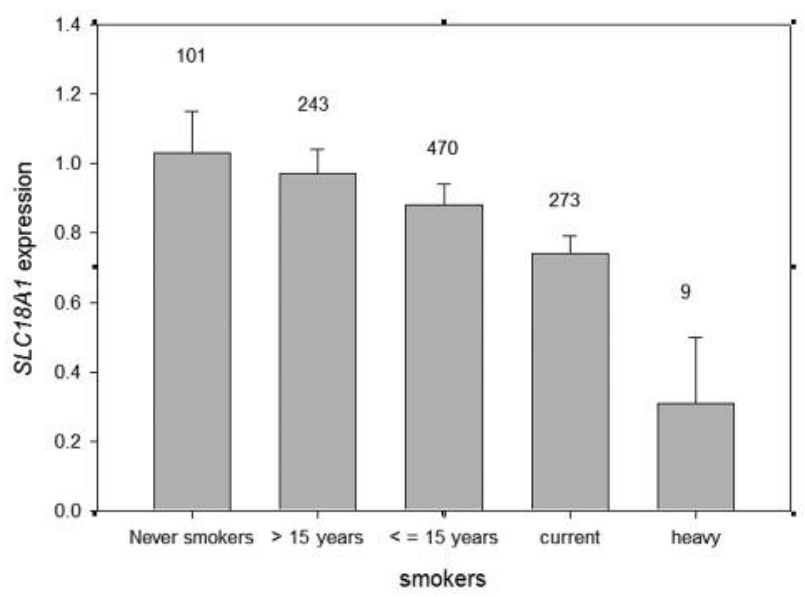

Figure 2. Solute carrier family 18 member 1 (SLC18A1) expression (mean+SEM) stratified by smoking status in The Cancer Genome Atlas lung cancer data. The variation was significant ( $p=0.035$ one-way ANOVA). Number of patients in each group is shown above corresponding error bar.

Many genes are related to personality, mental illness, and smoking $(25,26)$. But of these genes, only SLC18Al is known to be also involved in cancer $(12,13,27)$.

Immune checkpoint inhibitors (ICIs) have emerged as a new treatment option for patients with cancer, especially advanced NSCLC. ICIs can prolong survival, compared to chemotherapy alone, in ever-smokers. However, ICIs mostly fail to improve survival in never-smokers (28).

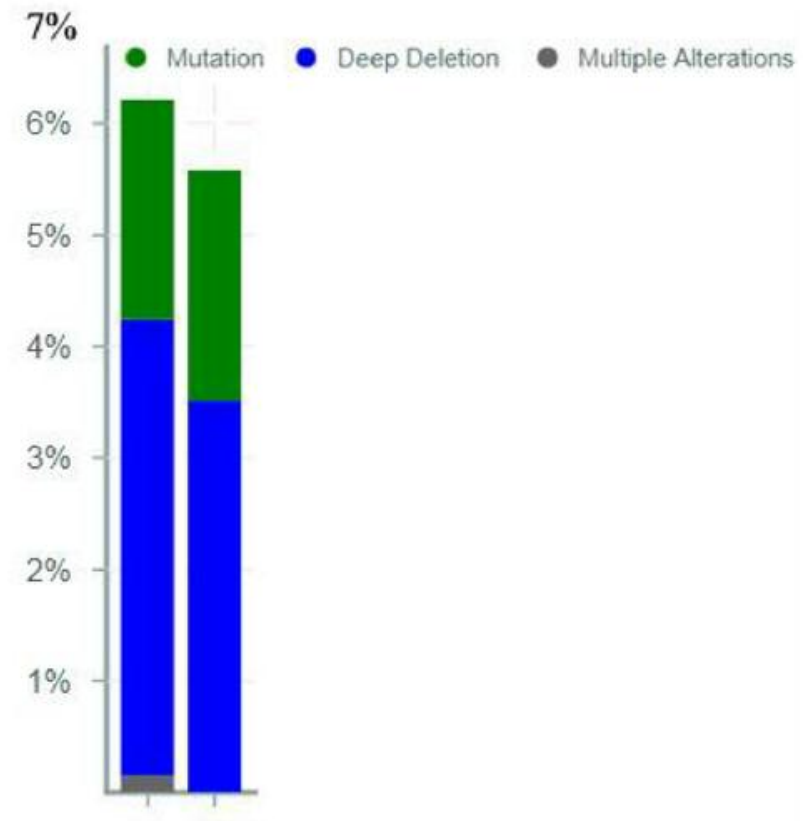

Ad SCC

Figure 3. Frequency of alteration of solute carrier family 18 member 1 (SLC18A1) gene in lung cancer by histology. Ad: Adenocarcinoma; SCC: squamous cell carcinoma.

Rizvi et al. assessed the effects of smoking on mutations and pembrolizumab response in NSCLC (29). According to the tumor molecular signature of smoking (frequency of $\mathrm{C} \rightarrow \mathrm{A}$ transversions in lung cancer exomes), Rizvi et al. 


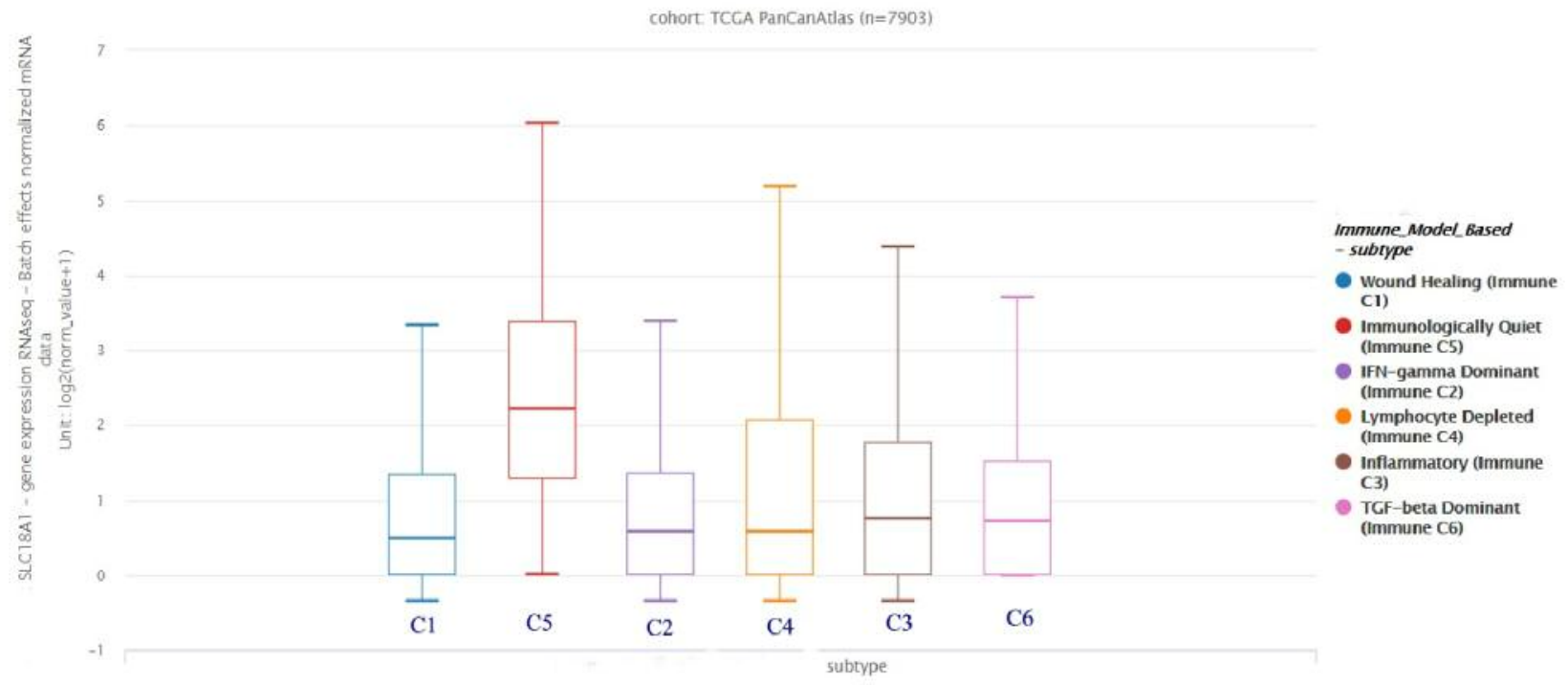

Figure 4. Solute carrier family 18 member 1 (SLC18A1) expression by immune model-based subtypes in The Cancer Genome Atlas PanCan Atlas $(p<0.001$, one-way ANOVA). Expression is higher in immune subtype C5, immunologically-quiet tumors.

cohort: TCGA PanCanAtlas $(n=7903)$

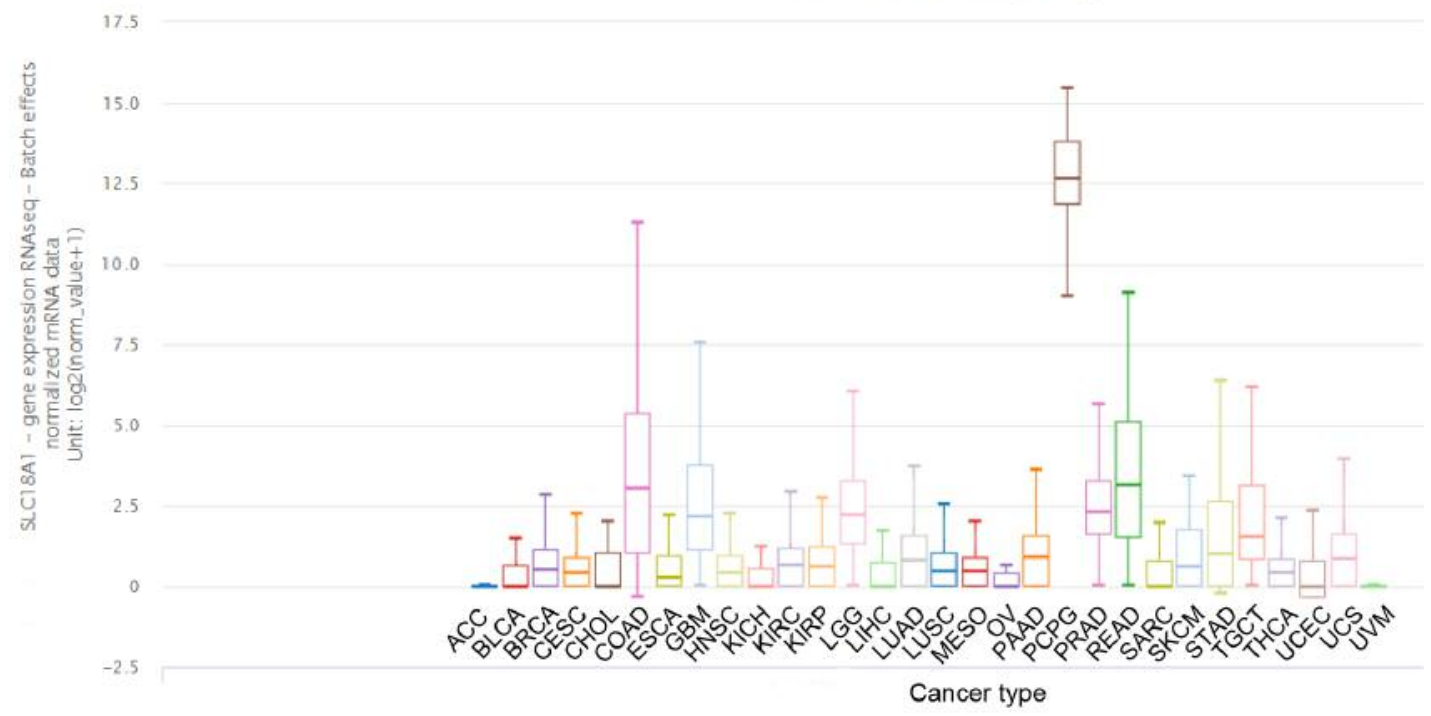

Figure 5. Solute carrier family 18 member 1 (SLC18A1) expression by cancer type ( $p<0.001$, one-way ANOVA). SLC18A1 is most highly expressed in pheochromocytoma and paraganglioma, $P C P G$.

Table II. Programmed cell death 1 (PDCD1) gene mutations in 1,299 tumors. The oncogenic function of these mutations is unknown.

\begin{tabular}{lccccr}
\hline Sample ID & Protein change & Mutation type & Copy number & COSMIC allelic frequency (T) & Number of mutants in sample \\
\hline TCGA-55-8616-01 & R104L & Missense & Diploid & 0.24 & 432 \\
TCGA-86-8073-01 & S109I & Missense & Diploid & 0.19 & 1337 \\
TCGA-97-81 79-01 & S137R & Missense & Gain & 0.2 & 151 \\
TCGA-78-7536-01 & T205N & Missense & Diploid & 0.26 & 594 \\
\hline
\end{tabular}




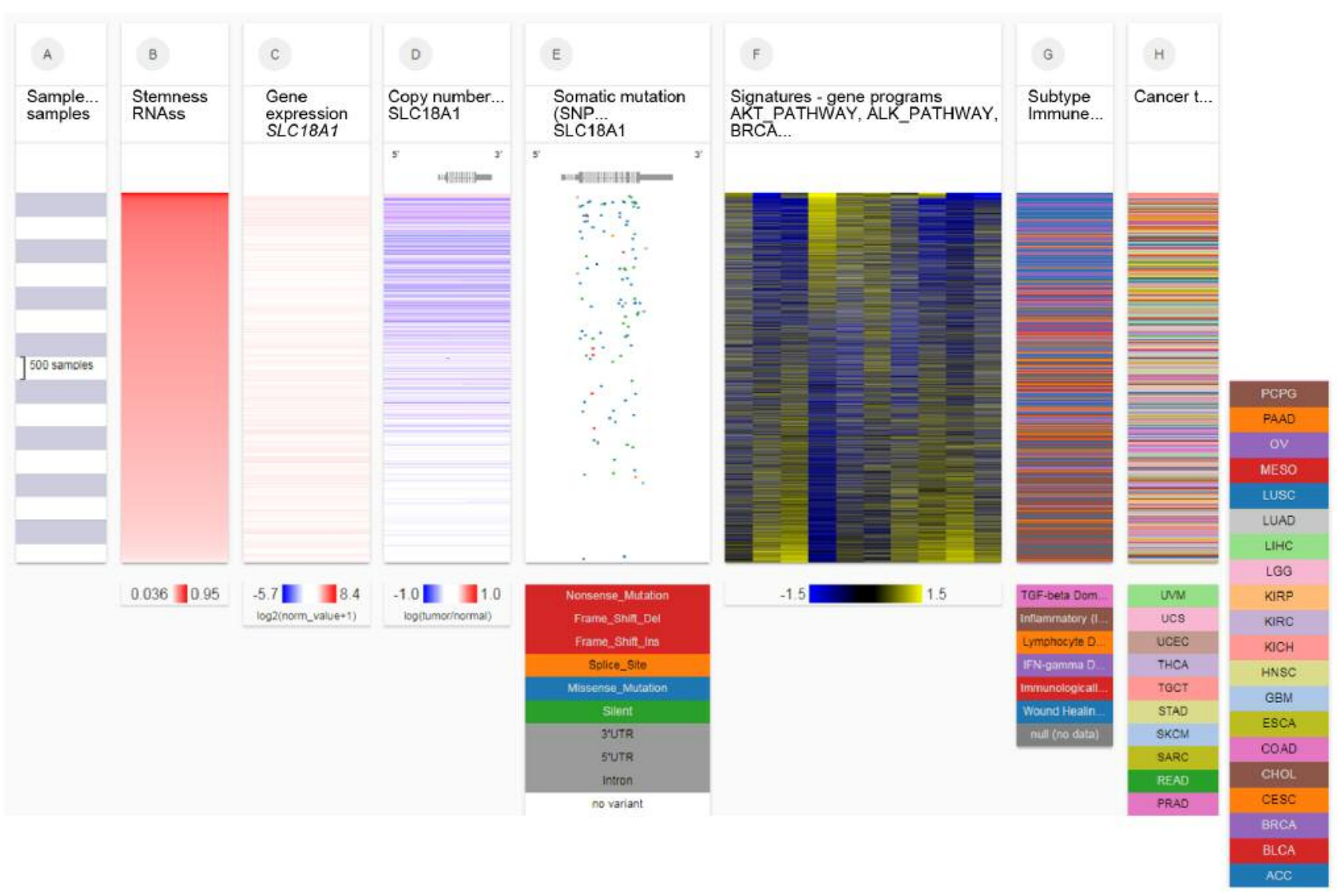

Figure 6. A total of 7,903 PanCan Atlas samples (rows) by seven genomics columns. Each row corresponds to a single sample. The first sample column is followed by the seven data columns. The rows are sorted on the left-most data column and sub-sorted on subsequent columns. Data columns, starting at the left, are stemness score, SLC18A1 gene expression, copy numbers, and mutations, scores for various gene programs, immune subtype, and cancer type. Higher stemness is indicated with brighter red. The mutations column E shows a gene diagram at the top with exons in alternating light and dark grey boxes. For each sample, the position of the mutation is marked in relation to the gene diagram at the top. Mutations are colored by their functional impact with deleterious mutations in red, and missense mutations and in-frame indels (an insertion or deletion of bases) in blue. Gene expression is colored red to blue for high to low expression. The gene program score is colored yellow to blue for high to low scores. The immune-based subtype and cancer type are colored by their values (https://xenabrowser.net). Stemness is defined by the ability to self-renew and differentiate. Unlike normal stem cells, which differentiate into healthy, mature cell types, cancer stem cells differentiate into cancer cells.

defined tumor samples as transversion high (TH, eversmoking signature) or transversion low (TL, never-smoking signature). Patients with TH molecular signature had higher mutational burden and showed better clinical benefit from pembrolizumab. This suggests that smoking status might be a predictive marker for clinical benefit from ICIs. Indeed, the expression of PD1 and its ligands PD-L1 and PD-L2, which predict response to pembrolizumab and nivolumab, is heterogeneous within kirsten rat sarcoma virus (KRAS)mutant NSCLC and suggests an inducible expression of PDL1 by smoking (30).

Both Keytruda ${ }^{\circledR}$ (pembrolizumab) and Opdivo ${ }^{\circledR}$ (nivolumab) are monoclonal antibodies that bind to the PD1 receptor found on T-cells and block its interaction with PD-L1 and PD-L2 (31). Two of the approved indications for Keytruda are based on a
US Food and Drug Administration-approved test for tumor expression of PD-L1, namely NSCLC and gastric cancer. Opdivo is indicated for both these cancer types without this limitation. Interestingly, most types of cancer for which these drugs are indicated are associated with smoking (NSCLC, gastric cancer, head and neck squamous cell carcinoma, renal cell carcinoma, urothelial carcinoma, hepatocellular carcinoma, but not melanoma) (https://dailymed.nlm.nih.gov/dailymed/ index.cfm Search "Keytruda" and "Opdivo").

Smoking may be related to cancer in two distinct ways: i) Systemic suppression of the immune response producing cancer that is susceptible to Keytruda and Opdivo. ii) Direct irritation producing tumors not susceptible to these agents. Where both mechanisms are present, there might be intermediate susceptibility. 
For unknown reasons, a small proportion of TL neversmokers show clinical benefit from pembrolizumab. This small proportion may correspond with the frequency of alteration of SLC18A1 in lung cancer (Figure 3). Because of the good response of this small group, it may be worthwhile assessing SLC18A1 expression prior to treatment and gene alteration as markers for potential clinical benefit from ICIs in never-smokers. If SLC18A1 expression is low or SLC18A1 is mutated, a never-smoker may respond well to ICIs, despite TL never-smoker mutation status. Higher SLC18A1 expression levels would cause the tumor to fall into the C5 immunologically-quiet group, as is the case with squamous cell carcinoma, and it would, therefore, be less likely to respond to ICIs (Figure 1). SLC18A1 might complement other biomarkers currently under study in relation to PD1/PD-L1 inhibition (32).

\section{References}

1 Feng H, Wang X, Zhang Z, Tang C, Ye H, Jones L, Lou F, Zhang D, Jiang S, Sun H, Dong H, Zhang G, Liu Z, Dong Z, Guo B, Yan H, Yan C, Wang L, Su Z, Li Y, Nandakumar V, Huang XF, Chen SY and Liu D: Identification of genetic mutations in human lung cancer by targeted sequencing. Cancer Inform 14: 83-93, 2015.

2 Gandhi L, Rodriguez-Abreu D, Gadgeel S, Esteban E, Felip E, De Angelis F, Domine M, Clingan P, Hochmair MJ, Powell SF, Cheng SYS, Bischoff HG, Peled N, Grossi F, Jennens RR, Reck M, Hui R, Garon EB, Boyer M, Rubio-Viqueira Bn, Novello S, Kurata T, Gray JE, Vida J, Wei Z, Yang J, Raftopoulos H, Pietanza MC and Garassino MC: Pembrolizumab plus chemotherapy in metastatic non-small-cell lung cancer. N Engl J Med 378: 2078-2092, 2018.

3 Hellmann MD, Ciuleanu TE, Pluzanski A, Lee JS, Otterson GA, Audigier-Valette C, Minenza E, Linardou H, Burgers S, Salman P, Borghaei H, Ramalingam SS, Brahmer J, Reck M, O’Byrne KJ, Geese WJ, Green G, Chang H, Szustakowski J, Bhagavatheeswaran P, Healey D, Fu Y, Nathan F and Paz-Ares L: Nivolumab plus ipilimumab in lung cancer with a high tumor mutational burden. N Engl J Med 378: 2093-2104, 2018.

4 Itkin O, Nemets B and Einat H: Smoking habits in bipolar and schizophrenic outpatients in southern Israel. J Clin Psychiatry 62: 269-272, 2001.

5 Weiser M, Reichenberg A, Grotto I, Yasvitzky R, Rabinowitz J, Lubin G, Nahon D, Knobler HY and Davidson M: Higher rates of cigarette smoking in male adolescents before the onset of schizophrenia: a historical-prospective cohort study. Am J Psychiatr 161: 1219-1223, 2004.

6 Lohoff FW, Weller AE, Bloch PJ, Buono RJ, Doyle GA, Ferraro TN and Berrettini WH: Association between polymorphisms in the vesicular monoamine transporter 1 gene (VMAT1/SLC18A1) on chromosome $8 \mathrm{p}$ and schizophrenia. Neuropsychobiology 57 : 55-60, 2008.

7 Richards M, Iijima Y, Kondo H, Shizuno T, Hori H, Arima K, Saitoh $\mathrm{O}$ and Kunugi $\mathrm{H}$ : Association study of the vesicular monoamine transporter 1 (VMAT1) gene with schizophrenia in a Japanese population. Behav Brain Funct 2: 39, 2006.
8 Galaktionova DI, Gareeva AE, Khusnutdinova EK and Nasedkina TV: The association of polymorphisms in SLC18A1, TPHI and RELN genes with risk of paranoid schizophrenia. Mol Biol (Mosk) 48: 629-639, 2014.

9 Lohoff FW, Dahl JP, Ferraro TN, Arnold SE, Gallinat J, Sander $\mathrm{T}$ and Berrettini WH: Variations in the vesicular monoamine transporter 1 gene (VMAT1/SLC18A1) are associated with bipolar I disorder. Neuropsychopharmacology 31: 2739-2747, 2006.

10 Lohoff FW, Hodge R, Narasimhan S, Nall A, Ferraro TN, Mickey BJ, Heitzeg MM, Langenecker SA, Zubieta JK, Bogdan R, Nikolova YS, Drabant E, Hariri AR, Bevilacqua L, Goldman $\mathrm{D}$ and Doyle GA: Functional genetic variants in the vesicular monoamine transporter 1 modulate emotion processing. Mol Psychiatry 19: 129-139, 2014.

11 Noroozi R, Ghafouri-Fard S, Omrani MD, Habibi M, Sayad A and Taheri M: Association study of the vesicular monoamine transporter 1 (VMAT1) gene with autism in an Iranian population. Gene 625: 10-14, 2017.

12 Anlauf M, Eissele R, Schafer MK, Eiden LE, Arnold R, Pauser U, Kloppel G and Weihe E: Expression of the two isoforms of the vesicular monoamine transporter (VMAT1 and VMAT2) in the endocrine pancreas and pancreatic endocrine tumors. $\mathrm{J}$ Histochem Cytochem 51: 1027-1040, 2003.

13 Zhang D, Li Z, Xu X, Zhou D, Tang S, Yin X, Xu F, Li H, Zhou Y, Zhu T, Deng H, Zhang S, Huang Q, Wang J, Yin W, Zhu Y and Lai M: Deletions at SLC18A1 increased the risk of CRC and lower SLC18A1 expression associated with poor CRC outcome. Carcinogenesis 38: 1057-1062, 2017.

14 Vivian J, Rao AA, Nothaft FA, Ketchum C, Armstrong J, Novak A, Pfeil J, Narkizian J, Deran AD, Musselman-Brown A, Schmidt H, Amstutz P, Craft B, Goldman M, Rosenbloom K, Cline M, O'Connor B, Hanna M, Birger C, Kent WJ, Patterson DA, Joseph AD, Zhu J, Zaranek S, Getz G, Haussler D and Paten B: Toil enables reproducible, open source, big biomedical data analyses. Nat Biotechnol 35: 314-316, 2017.

15 Bland JM and Altman DG: Survival probabilities (the KaplanMeier method). BMJ 317: 1572-1580, 1998.

16 Lee SJ, Lee J, Park YS, Lee CH, Lee SM, Yim JJ, Yoo CG, Han SK and Kim YW: Impact of smoking on mortality of patients with non-small cell lung cancer. Thorac Cancer 5: 43-49, 2014.

17 Gao J, Aksoy BA, Dogrusoz U, Dresdner G, Gross B, Sumer SO, Sun Y, Jacobsen A, Sinha R, Larsson E, Cerami E, Sander $\mathrm{C}$ and Schultz N: Integrative analysis of complex cancer genomics and clinical profiles using the cBioPortal. Sci Signal 6: 11, 2013.

18 Thorsson V, Gibbs DL, Brown SD, Wolf D, Bortone DS, Ou Yang TH, Porta-Pardo E, Gao GF, Plaisier CL, Eddy JA, Ziv E, Culhane AC, Paull EO, Sivakumar IKA, Gentles AJ, Malhotra R, Farshidfar F, Colaprico A, Parker JS, Mose LE, Vo NS, Liu J, Liu Y, Rader J, Dhankani V, Reynolds SM, Bowlby R, Califano A, Cherniack AD, Anastassiou D, Bedognetti D, Rao A, Chen K, Krasnitz A, Hu H, Malta TM, Noushmehr H, Pedamallu CS, Bullman S, Ojesina AI, Lamb A, Zhou W, Shen H, Choueiri TK, Weinstein JN, Guinney J, Saltz J, Holt RA, Rabkin CE, Lazar AJ, Serody JS, Demicco EG, Disis ML, Vincent BG and Shmulevich L: The immune landscape of cancer. Immunity 48: 812-830, 2018.

19 Lindgren D, Eriksson P, Krawczyk K, Nilsson H, Hansson J, Veerla S, Sjölund J, Höglund M, Johansson ME and Axelson H: 
Cell-type-specific gene programs of the normal human nephron define kidney cancer subtypes. Cell Reports 20: 1476-1489, 2017.

20 NIH/NCBI: SLC18A1 solute carrier family 18 member A1 [Homo sapiens (human)] Gene ID: 6570. https:// www.ncbi.nlm.nih.gov/gene/6570.

21 Lo MT, Hinds DA, Tung JY, Franz C, Fan CC, Wang Y, Smeland OB, Schork A, Holland D, Kauppi K, Sanyal N, EscottPrice V, Smith DJ, O’Donovan M, Stefansson H, Bjornsdottir G, Thorgeirsson TE, Stefansson K, McEvoy LK, Dale AM, Andreassen $\mathrm{OA}$ and Chen $\mathrm{CH}$ : Genome-wide analyses for personality traits identify six genomic loci and show correlations with psychiatric disorders. Nat Genet 49: 152-156, 2017.

22 Won E, Han KM, Kang J, Kim A, Yoon HK, Chang HS, Park JY, Lee MS, Greenberg T, Tae WS and Ham BJ: Vesicular monoamine transporter 1 gene polymorphism and white matter integrity in major depressive disorder. Prog Neuropsychopharmacol Biol Psychiatry 77: 138-145, 2017.

23 Dutta N, Helton SG, Schwandt M, Zhu X, Momenan R and Lohoff FW: Genetic variation in the vesicular monoamine transporter 1 (VMAT1/SLC18A1) gene and alcohol withdrawal severity. Alcohol Clin Exp Res 40: 474-481, 2016.

24 Vaht M, Kiive E, Veidebaum T and Harro J: A Functional vesicular monoamine transporter 1 (VMAT1) gene variant is associated with affect and the prevalence of anxiety, affective, and alcohol use disorders in a longitudinal populationrepresentative birth cohort study. Int J Neuropsychopharmacol 19: 2016.

25 Verde Z, Santiago C, Gonzalez-Moro JMR, de Lucas Ramos P, Martin SL, Bandras F, Lucia A and Gomez-Gallego F: Smoking genes: a genetic association study. PloS one 6: e26668, 2011.

26 Gandal MJ, Haney JR, Parikshak NN, Leppa V, Ramaswami G, Hartl C, Schork AJ, Appadurai V, Buil A, Werge TM, Liu C, White KP, Horvath S and Geschwind DH: Shared molecular neuropathology across major psychiatric disorders parallels polygenic overlap. Science 359: 693, 2018.
27 Temple W, Mendelsohn L, Kim GE, Nekritz E, Gustafson WC, Lin L, Giacomini K, Naranjo A, Van RC, Yanik GA, Kreissman SG, Hogarty M, Matthay KK and DuBois SG: Vesicular monoamine transporter protein expression correlates with clinical features, tumor biology, and MIBG avidity in neuroblastoma: A report from the Children's Oncology Group. Eur J Nucl Med Mol Imaging 43: 474-481, 2016.

$28 \mathrm{Kim} \mathrm{JH}$, Kim HS and Kim BJ: Prognostic value of smoking status in non-small-cell lung cancer patients treated with immune checkpoint inhibitors: A meta-analysis. Oncotarget 8: 9314993155, 2017.

29 Rizvi NA, Hellmann MD, Snyder A, Kvistborg P, Makarov V, Havel JJ, Lee W, Yuan J, Wong P, Ho TS, Miller ML, Rekhtman N, Moreira AL, Ibrahim F, Bruggeman C, Gasmi B, Zappasodi R, Maeda Y, Sander C, Garon EB, Merghoub T, Wolchok JD, Schumacher TN and Chan TA: Mutational landscape determines sensitivity to PD-1 blockade in non-small cell lung cancer. Science 348(6230): 124-128, 2015.

30 Calles A, Liao X, Sholl LM, Rodig SJ, Freeman GJ, Butaney M, Lydon C, Dahlberg SE, Hodi FS, Oxnard GR, Jackman DM and Janne PA: Expression of PD-1 and its ligands, PD-L1 and PDL2, in smokers and never smokers with KRAS-mutant lung cancer. J Thorac Oncol 10: 1726-1735, 2015.

31 Barbee MS, Ogunniyi A, Horvat TZ and Dang TO: Current status and future directions of the immune checkpoint inhibitors ipilimumab, pembrolizumab, and nivolumab in oncology. Ann Pharmacother 49: 907-937, 2015.

32 Maleki VS, Garrigos C and Duran I: Biomarkers of response to PD-1/PD-L1 inhibition. Crit Rev Oncol Hematol 116: 116-124, 2017. 